\title{
"SUPER ZID": DESENVOLVIMENTO DE UM JOGO EDUCACIONAL DIGITAL PARA APOIAR O COMBATE AO AEDES AEGYPTI
}

\author{
Carina Fernanda Zortea - carinazortea13@ gmail.com - UFSM/FW \\ Silvana Kliszcz - silvana@websetbrasil.com - UFSM/FW \\ Fábio José Parreira - fabioparreira@ gmail.com - UFSM/FW \\ Sidnei Renato Silveira - sidneirenato.silveira@gmail.com - UFSM/FW
}

\begin{abstract}
Resumo. Este artigo apresenta o desenvolvimento de um jogo educacional digital para apoiar o combate ao mosquito Aedes Aegypti, o "Super ZID". O jogo foi desenvolvido para alunos do ensino fundamental, na faixa etária entre sete e nove anos de idade, podendo ser utilizado por meio de um browser web, e conta com algumas fases para que a criança possa aprender a identificar os focos de criação do mosquito Aedes Aegypti e, por meio de uma forma lúdica, incentivar o aprendizado.
\end{abstract}

Palavras-Chave. Jogos Educacionais Digitais, Aedes Aegypti, Informática na Educação.

\section{"SUPER ZID": DEVELOPMENT OF A DIGITAL EDUCATIONAL GAME TO SUPPORT COMBATING THE AEDES AEGYPTI}

Abstract. This paper presents a digital educational game to help combat the Aedes Aegypti the "Super ZID". The game was developed for elementary school students, aged between seven and nine years old and can be used through a web browser and has some stages so that the child can learn to identify outbreaks of breeding Aedes Aegypti and through a playful way to encourage learning.

Keywords. Digital Educational Games, Aedes Aegypty, Computer in Education.

\section{INTRODUÇÃO}

Atualmente, a preocupação de se combater o mosquito Aedes Aegypti tem se tornado nacional e internacional, devido à gravidade das doenças transmitidas pelo mesmo (FAVERO, 2016). Neste contexto, acredita-se que o desenvolvimento de um jogo educacional digital para apoiar o combate ao Aedes Aegypti mostra-se como uma oportunidade para, de uma forma lúdica, conscientizar e explicar para os alunos das séries iniciais do Ensino Fundamental como eliminar os focos de proliferação do mosquito.

Sendo assim, este artigo apresenta o desenvolvimento de um protótipo de jogo educacional digital para apoiar o combate ao mosquito Aedes Aegypti, o Super ZID, voltado para crianças de sete a nove anos de idade, com o intuito de apoiar os processos de ensino e de aprendizagem sobre a prevenção de doenças transmitidas por este mosquito. A aplicação deste jogo pode tornar os processos de ensino e de aprendizagem mais agradáveis e menos cansativos, estimulando a aprendizagem das crianças por meio de um mundo lúdico e divertido.

Sabe-se da importância que o computador tem na Educação como agente transformador e a importância do software educacional (tais como os jogos 
educacionais digitais) como corresponsável nessa transformação, apoiando os processos de ensino e de aprendizagem. Vale ressaltar a importância da concepção e desenvolvimento de softwares educacionais como instrumentos potencializadores da aprendizagem em que a reciclagem de informações transforma os paradigmas tradicionais da Educação, possibilitando práticas pedagógicas inovadoras (FALKEMBACH, 2005).

Segundo Tiellet et al. (2007), os jogos educacionais digitais apresentam um conteúdo a ser estudado e atividades práticas com objetivos educacionais baseados no lazer e diversão. São atrativos e podem ser muito divertidos. A motivação do aprendiz acontece como consequência da abordagem pedagógica adotada que utiliza a exploração livre e o lúdico.

Para dar conta desta proposta, o artigo está dividido nas seguintes seções: a seção 2 apresenta um referencial teórico, conceituando os jogos educacionais digitais. $\mathrm{O}$ jogo educacional digital desenvolvido, bem como sua validação, são apresentados na seção 3. Encerrando o artigo são apresentadas as considerações finais e as referências empregadas.

\section{JOGOS EDUCACIONAIS DIGITAIS}

Segundo Parreira et al. (2016), os jogos educacionais baseiam-se no interesse que a criança tem de jogar, brincar e de descobrir o diferente. O jogo prende a atenção das crianças por meio de ambientes atraentes e gratificantes, com recursos poderosos de estímulo para o desenvolvimento integral do aluno. Esses métodos desempenham um papel muito importante na evolução do aprendizado, pois desenvolvem o aumento da atenção, disciplina, autocontrole, respeito a regras e aumentam as habilidades perceptivas e motoras dependendo do que cada jogo necessite.

Os jogos educacionais digitais são elaborados para divertir os alunos e aumentar o conhecimento e melhorar a aprendizagem de conceitos, conteúdos e habilidades contidas no jogo, proporcionando para o aluno um ambiente rico e complexo. Para alguns pesquisadores estes jogos são chamados de "micromundos", por fornecer um mundo imaginário a ser explorado pelos alunos (PARREIRA et al. 2016).

Segundo Cuperschmid e Hildebrand (2013), os jogos educacionais digitais, tentam ensinar e prever a prática, enquanto motivam o aprendizado. Como efeito positivo, estimulam o desenvolvimento do pensamento crítico e da habilidade de observar, tentar e errar. Estimulam, também, a estratégia, a exploração e o desenvolvimento cognitivo nas habilidades visuais como representação visual, atenção visual e reconhecimento icônico. As características que asseguram eficiência do aprendizado baseado em jogos são o seu envolvimento, a sua interatividade e a participação ativa que eles oferecem. Os jogos fornecem um retorno (feedback) interativo, o que é fundamental para o aprendizado.

Por oferecer praticas atrativas e inovadoras, proporcionando ao aluno a chance de aprender de forma mais atrativa, dinâmica e motivadora, os jogos educacionais podem se tornar auxiliares importantes do processo de ensino e aprendizagem. Para Behar (2009), para que os jogos possam ser utilizados para fins educacionais, os mesmos precisam ter objetivos de aprendizagem bem definidos e ensinar conteúdo da disciplina ao usuário, ou então, promover o desenvolvimento de estratégias ou habilidades importantes para ampliar a capacidade cognitiva e intelectual dos alunos.

Para Gebran (2009), o mais importante no desenvolvimento dos jogos educacionais digitais são as atividades que proporcionam a interatividade entre $o$ 
computador e o usuário. Existem vários níveis de interatividade, o importante é saber dosar para que o objetivo pedagógico seja alcançado, pois dependendo da ação proposta o aluno poderá imergir no conteúdo de forma agradável. Neste caso o aluno, sem saber, estará aprendendo de forma desafiadora e inovadora.

O que torna os jogos educacionais digitais interessantes e motivadores são os desafios, a fantasia e a curiosidade, além de oferecerem oportunidades para o aluno usar lógica, raciocínio e habilidades de organização para resolver problemas de uma forma mais atrativa do que normalmente ele está acostumado. Um jogo, por mais simples que possa ser, sempre pode apoiar o processo de aprendizagem de várias habilidades e conceitos, de maneira sofisticada para que os alunos não cansem do conteúdo (PARREIRA et al., 2016).

\section{SOLUÇÃO IMPLEMENTADA}

Desenvolveu-se um protótipo de jogo educacional digital, denominado "Super ZID”, para crianças entre 7 e 9 anos, para apoiar o combate ao mosquito Aedes Aegypti. $\mathrm{O}$ jogo educacional digital foi desenvolvido seguindo o modelo plataforma. $\mathrm{O}$ modelo plataforma é um gênero de jogos eletrônicos em que o jogador corre e pula entre plataformas e obstáculos, enfrentando inimigos e coletando objetos, bônus, etc. Desta forma o jogador, de uma forma divertida e fácil, passará pelas fases do jogo aprendendo e se divertindo.

As crianças devem identificar e eliminar os focos do mosquito Aedes Aegypti por meio de um personagem (o "Super ZID") que se movimenta pelo cenário recolhendo recipientes com água parada. Além disso, recebem mensagens informativas no decorrer das fases do jogo e, no final de cada fase o personagem enfrenta um mosquito para poder passar para a próxima.

O jogo tem, por objetivo, auxiliar as crianças a identificar os focos dos criadouros e de desenvolvimento do mosquito Aedes Aegypti. O jogo proporciona às crianças a capacidade de identificar os focos, fora do mundo lúdico do jogo, e como o público-alvo do jogo são crianças de 7 a 9 anos, aconselha-se que, ao identificar o foco no mundo real, a criança peça ajuda a um adulto para eliminá-lo. Este foco pode ser desde água parada em seus próprios brinquedos, ou em qualquer objeto que possa acumular água, até um objeto que possa trazer algum risco à criança.

O jogo possui dois personagens, o principal (comandado pelo usuário), e o mosquito. O personagem principal ("Super ZID”) realiza ações definidas pelo usuário quando o mesmo aperta teclas específicas que representam os comandos do jogo como, por exemplo, andar, pular obstáculos, percorrer o cenário e realizar as tarefas do jogo, tais como: ao colidir com algum objeto referente aos focos dos criadouros do mosquito, uma mensagem surgirá na tela sobre como este objeto se tornaria um criadouro e como combatê-lo. Quando o personagem colide com objetos que fazem o personagem acumular vida, armas e poderes (que servem para o final da fase quando o personagem principal encontra o mosquito) estes itens são coletados e podem ser utilizados posteriormente. Quando o personagem principal consegue passar pelo mosquito, ele passa para a próxima fase. O jogo conta com três fases:

- Na primeira fase o cenário é o de um centro urbano. Nesta fase o personagem principal percorre o cenário e precisa identificar os focos dos criadouros do mosquito Aedes Aegypti, além de recolher objetos para auxiliar o personagem para passar para a próxima fase; 
- Na segunda fase o cenário é um quintal e o interior de uma casa. Nesta fase o personagem principal percorre esses ambientes recolhendo os objetos e identificando os focos, eliminando-os para poder seguir para a próxima fase;

- O cenário da terceira fase é o perímetro rural (campo). As três fases seguem a mesma temática, onde o personagem principal percorre os cenários identificando os focos, recolhe os objetos para poder enfrentar o mosquito no final de cada fase, para passar para a próxima. Na terceira fase o jogador pode escolher entre voltar para o menu inicial, e jogar novamente o jogo, ou sair.

A metodologia a ser utilizada neste trabalho foi a dissertação-projeto, pois desenvolveu-se um protótipo de jogo educacional digital. Segundo Ribeiro e Zabadal (2010), na metodologia de dissertação-projeto, “...o pesquisador caracteriza determinado problema de algum aspecto técnico. Destaca a relevância de resolver esse problema. Desenvolve, então, um programa sistema ou mesmo um protótipo - para apresentar como prova de conceito da solução desse problema" (p. 96).

Para a modelagem dos cenários lúdicos que compõem o protótipo do jogo educacional digital "Super ZID", foi utilizada a técnica de storyboard. Um storyboard pode representar um esboço do modelo de uma aplicação e mostrar como seus elementos estarão organizados. Além disso, ajuda no planejamento do conteúdo de cada unidade, na disposição das mídias. O storyboard é o "rascunho" da aplicação permitindo aos responsáveis pelo projeto visualizarem sua estrutura de navegação, ou seja, discutirem a sequência do conteúdo e fazerem as revisões e o acompanhamento necessários (FALKEMBACH, 2005).

Utilizou-se, para o desenvolvimento do jogo, a ferramenta Construct 2, que possibilita a criação de jogos digitais em HTML5 (HyperText Markup Language). Esta ferramenta foi desenvolvida pela empresa Scirra Ltda. A ferramenta permite a criação rápida de jogos, por meio do estilo drag-and-drop (arrastar-soltar), usando um editor visual e um sistema de lógica baseada em comportamento (SCIRRA, 2016).

$\mathrm{Na}$ ferramenta Construct toda a programação de um jogo é feita de modo visual, utilizando o conceito de evento e ações, onde para cada evento pode-se definir uma ou mais ações. Uma das suas principais características é o desenvolvimento extremamente rápido de um jogo, pois a ferramenta é nativamente preparada com componentes e comportamentos prontos para uso. Basta que o desenvolvedor do jogo crie um objeto, adicione um comportamento ao mesmo e programe seus eventos e ações, tudo de forma visual (LARSEN, 2016).

O jogo conta com telas de textos, tela para escolher a fase, a tela inicial e a tela de Game Over. O primeiro contato do usuário com o jogo é por meio da tela Inicial (Figura 1), que conta com dois áudios, o primeiro saudando o jogador e informando o nome do jogo e o segundo, que informa que é necessário clicar no botão play representado por uma "seta", para iniciar o jogo. 

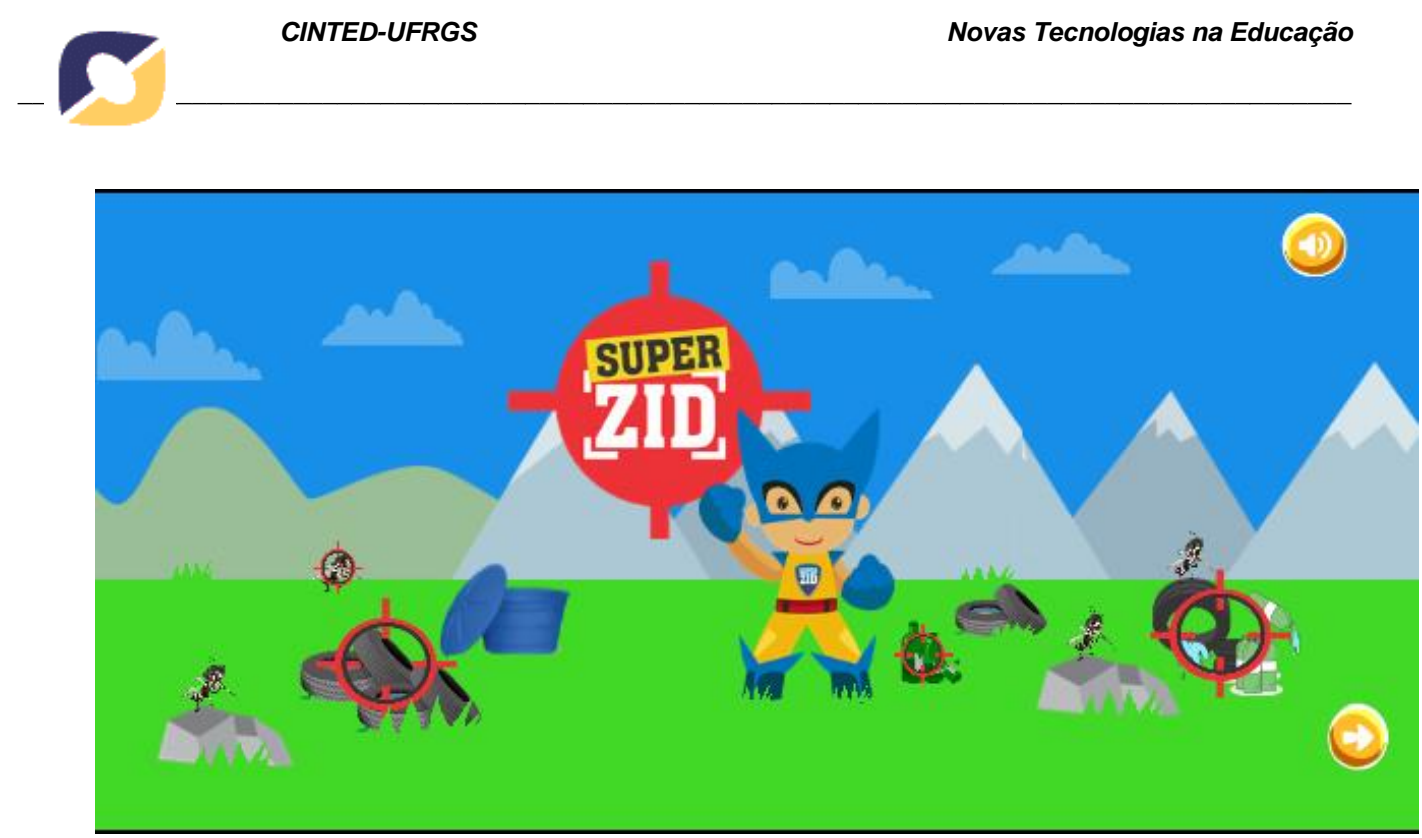

Figura 1: Tela de Início do jogo "SUPER ZID” (Fonte: Dos Autores, 2016)

A tela para escolher a fase para jogar conta com áudio informando que o jogador escolha a fase que deseja jogar. Nesta tela o jogo inicia apenas com a primeira fase liberada. Após passar pela primeira fase o jogador volta para esta tela e escolhe a próxima fase. Caso já tenha mais de uma fase liberada, o jogador pode escolher qual deseja jogar.

Todas as fases contêm telas com textos informativos sobre o mosquito e qual será o cenário que o jogador vai encontrar durante o jogo. A Figura 2 retrata a tela da primeira fase, em que o personagem (Super ZID) está se movimentando pelo cenário encontrando os focos dos criadouros do mosquito e enfrentando os mosquitos pelo caminho. Quando o personagem encontra os focos, ele deve encostar nos mesmos para poder destruir os possíveis criadouros do mosquito. O personagem deve, também, combater os mosquitos espalhados pelo cenário para poder chegar até o mosquito "chefe", para acabar de vez com a infestação de mosquito. Esta dinâmica testa, também, o quanto o jogador sabe sobre o assunto, pois os objetos muitas vezes fazem parte do cenário.

A primeira fase conta com duas telas: na primeira o personagem se depara com uma rua cheia de mosquitos, lixo, entulhos e garrafas, entre outros focos. Após vencer o mosquito "chefe", o personagem vai para a próxima tela que se assemelha ao subsolo de uma cidade (esgoto). Neste local o personagem encontra grandes desafios ao se deparar com mais mosquitos e focos e, ao final dessa tela, o personagem termina a primeira fase. Esta tela é apresentada na Figura 3. 


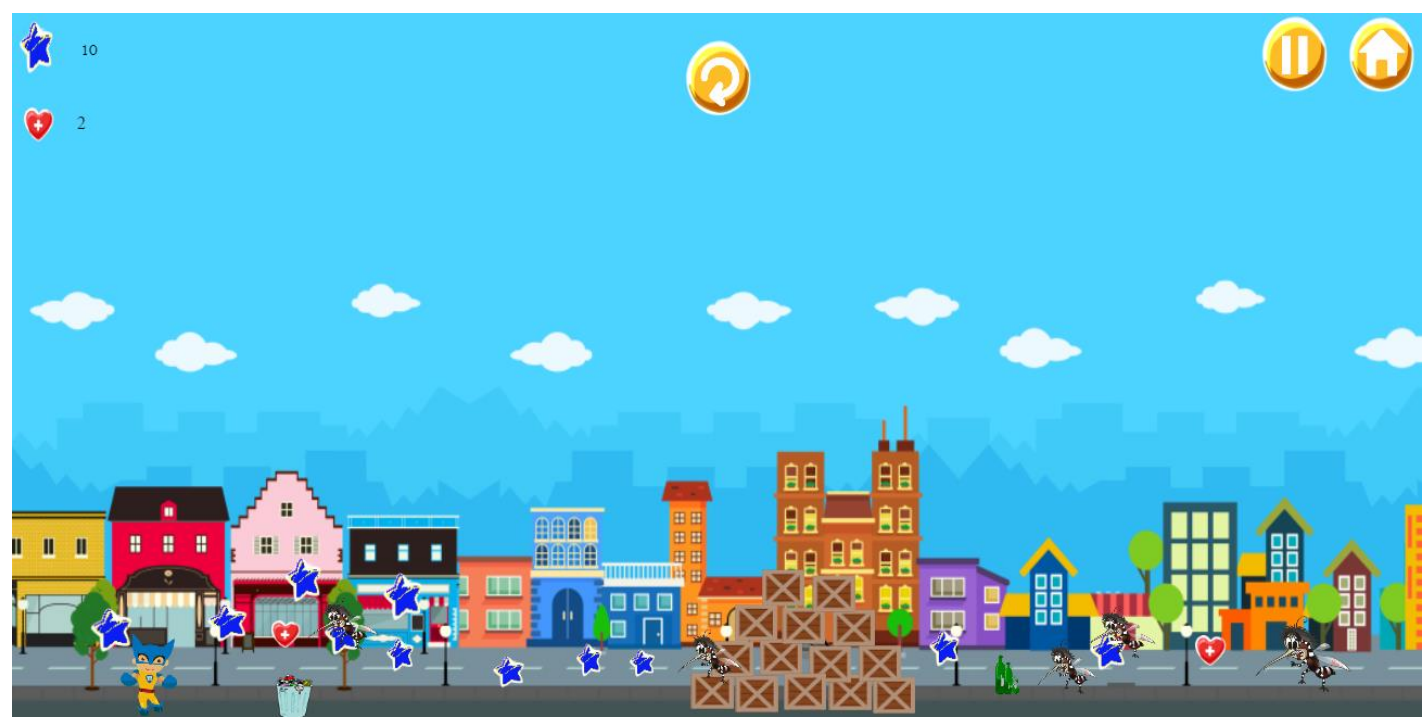

Figura 2: O personagem percorrendo o cenário identificando os focos dos criadouros do mosquito na primeira fase. (Fonte: Dos autores, 2016)

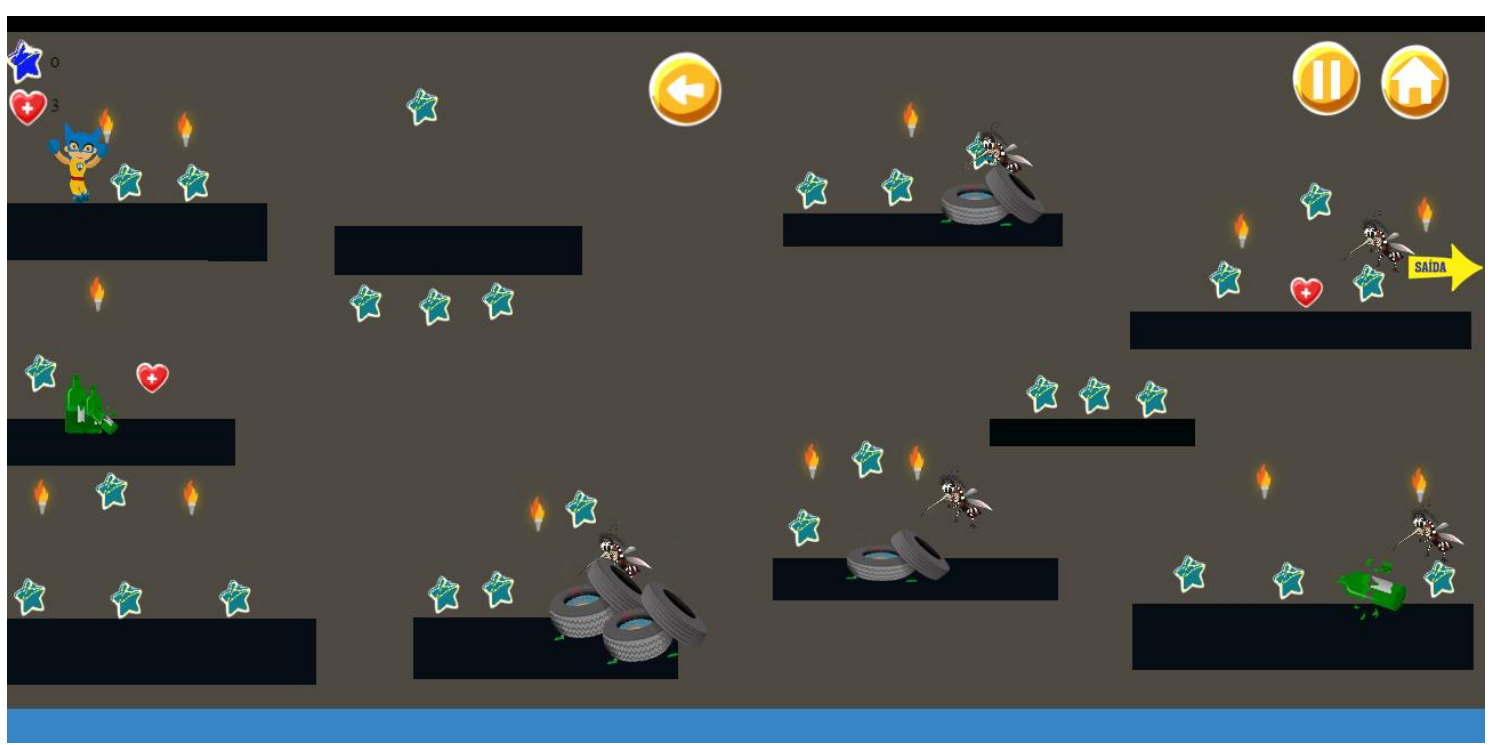

Figura 3: Segunda tela da primeira fase do jogo o Subsolo da cidade. (Fonte: Dos autores, 2016)

Na fase dois, o personagem sai do subsolo da cidade e anda por um gramado (quintal), recolhendo os objetos que acumulam água e destruindo os mosquitos. $\mathrm{O}$ personagem deve seguir caminhando até chegar em uma casa e entrar na mesma para procurar os focos. Esta fase contém duas telas: a primeira com o cenário do quintal e a segunda tela o interior de uma casa. A Figura 4 mostra a primeira tela da segunda fase, representando o quintal por onde o personagem caminha até chegar na casa. 

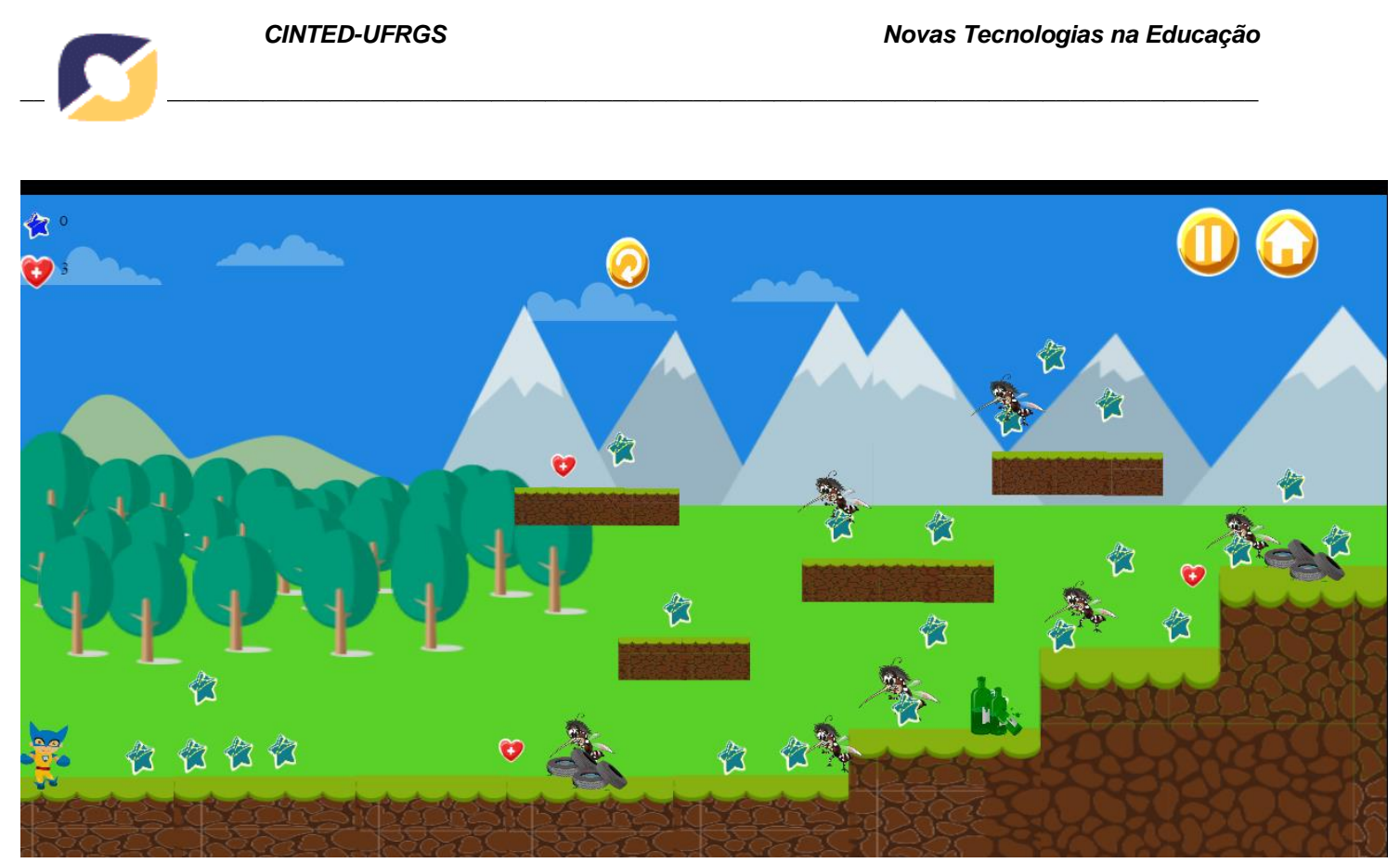

Figura 4: Primeira tela da Segunda fase, onde o personagem recolhe os focos e elimina os mosquitos (Fonte: Dos autores, 2016)

A terceira fase se passa no campo, onde o personagem percorre o cenário para recolher os focos e destruir os mosquitos. Todas as fases contêm a mesma temática o que muda de uma fase para outra é o cenário e alguns focos, pois buscou-se retratar os principais focos encontrados em cada ambiente.

\subsection{TESTES E VALIDAÇÃO}

Durante o desenvolvimento do protótipo do jogo proposto foram realizados testes pelos participantes da equipe de desenvolvimento, para verificar as funcionalidades do mesmo, bem como a correção das atividades propostas.

Após a implementação do protótipo do jogo proposto, o mesmo foi validado por meio da aplicação com alunos da faixa etária proposta, sendo a validação realizada em duas escolas, uma localizada em Taquaruçu do sul - RS e outra localizada em Frederico Westphalen - RS, avaliando o impacto e aceitação pelos alunos que avaliaram o protótipo do jogo.

A primeira escola em que foi realizada a validação do jogo foi a Escola Municipal de Ensino Fundamental Afonso Balestrin, em Taquaruçu do sul - RS, no dia 13 de novembro de $2016 \mathrm{com}$ a turma 41, do $4^{\circ}$ ano. Primeiramente os responsáveis pela Direção da Escola foram contatados, para que se buscasse a permissão para se realizar a validação. Cabe destacar que todos os procedimentos éticos para a participação dos alunos foram seguidos.

A turma era composta por 22 alunos, sendo 11 meninas e 11 meninos e o laboratório de informática da escola contava com 19 computadores mais um computador para o professor. Entretanto, apenas 16 computadores estavam funcionando. Os computadores contavam com sistema operacional Microsoft Windows e navegador Chrome. Os equipamentos eram antigos e a conexão com a Internet precária. Além disso, não funcionava o som nos equipamentos. Mesmo assim, foi possível utilizar o jogo e realizar a observação. Para realizar a observação foi utilizado um roteiro, preenchido pelos autores deste artigo, durante a validação. A validação durou em torno de 45 minutos. 
A professora responsável pelos alunos conduziu os mesmos até o laboratório de informática e explicou como procederia a validação e, posteriormente, passou a palavra para a equipe de desenvolvimento do jogo. Primeiramente realizou-se uma introdução sobre o funcionamento do jogo. Também foram realizadas perguntas para os alunos sobre o conhecimento deles sobre as doenças que a picada do mosquito Aedes Aegypti pode transmitir e se sabiam identificar os focos. Após essa breve introdução os alunos começaram a jogar, sendo acompanhados pela professora e pela equipe de pesquisadores que estava participando da validação.

Ao final da validação do jogo foram realizadas algumas perguntas para os alunos, sobre suas impressões em relação ao jogo: se os mesmos tinham gostado do jogo e se tinham alguma sugestão para melhorá-lo. Todos responderam que gostaram do jogo e que não tinham sugestões de melhoria.

Também foi aplicado um questionário para a professora, sobre a importância dos jogos educacionais e quais benefícios trariam para os alunos. Por meio do questionário aplicado para a professora responsável pelos alunos, buscou-se saber com que frequência os alunos utilizavam o laboratório e que tipo de atividades eram realizadas e qual a importância dos jogos educacionais para a formação dos alunos. Constatou-se, analisando as respostas da professora, que os alunos frequentam uma vez por semana o laboratório de informática, desenvolvendo atividades como pesquisas na Internet e utilização de jogos educacionais, além de noções básicas de informática. Segundo a Sra. Susana Schwartz Basso, os alunos demostram maior interesse por jogos auxiliando como complementação ao ensino ministrado em sala de aula. A Figura 5 mostra o momento em que os alunos estavam testando o jogo no laboratório. Cabe destacar que a escola possui autorização dos pais e/ou responsáveis para usar as imagens dos alunos. Mesmo assim, preferiu-se que os rostos dos mesmos não aparecessem nas fotos.

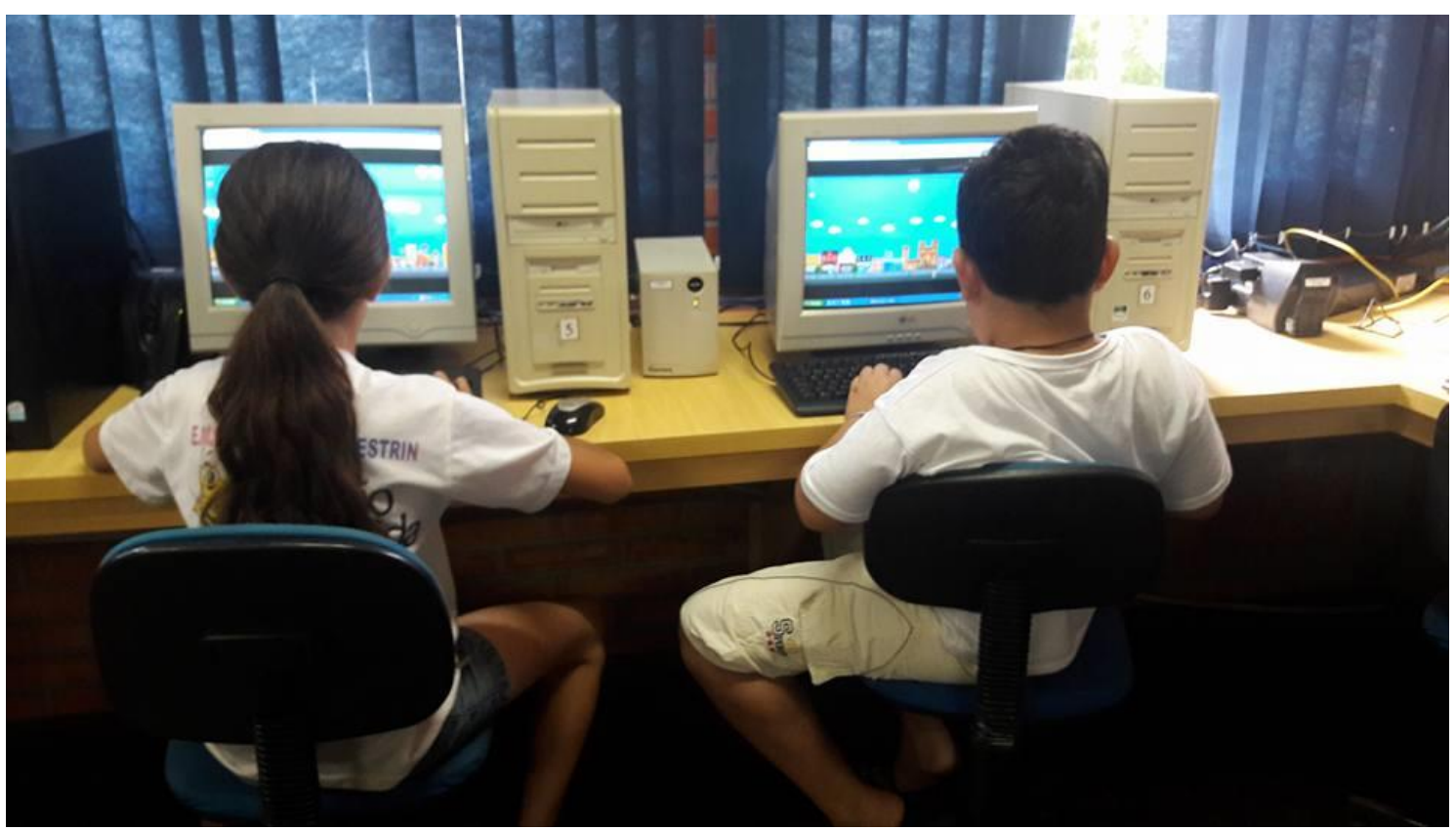

Figura 5. Validação do jogo "Super Zid" com os alunos do $4^{\circ}$ ano na Escola Afonso Balestrin de Taquaruçu do Sul - RS (Fonte: Dos autores, 2016)

A validação na Escola de Ensino Fundamental Nossa Senhora Auxiliadora localizada em Frederico Westphalen - RS, foi realizada no dia 01 de dezembro de 2016 com três turmas, duas do $2^{\mathrm{a}}$ ano e uma do $4^{\mathrm{a}}$ ano. O laboratório conta com 12 
computadores e mais um para a professora. Os computadores possuem o sistema operacional Microsoft Windows e o navegador utilizado foi o Chrome. Todos os computadores estavam funcionando. Os sons dos equipamentos estavam funcionando, entretanto, o som foi desligado pelo barulho excessivo, após a $1^{\mathrm{a}}$ turma realizar a validação.

A professora que acompanhou a equipe e os alunos foi a professora responsável pelo laboratório. A primeira turma contava com 18 alunos, sendo 11 meninos e 7 meninas. A segunda turma contava com 17 alunos, sendo 8 meninos e 9 meninas. A terceira turma contava com 21 alunos, sendo 8 meninos e 13 meninas.

Primeiramente os responsáveis pela Direção da Escola foram contatados, para que se buscasse a permissão para se realizar a validação. Inicialmente realizou-se uma breve introdução sobre o jogo com relação ao seu funcionamento e foram feitas algumas perguntas para os alunos sobre o conhecimento dos mesmos em relação ao mosquito e como identificar os focos. Após esta breve introdução os alunos iniciaram o jogo. A primeira turma demonstrou algumas dificuldades em conseguir passar de fase e para achar o local da tela para alcançar o fim da fase. A segunda turma demonstrou menos dificuldade do que a primeira, conseguindo concluir todas as fases com grande facilidade. A terceira turma precisou de mais auxílio para concluir as fases, encontrando dificuldades para chegar ao final da fase e de descobrir alguns comandos, tais como atirar, saltar. Estas dificuldades foram sanadas com o auxílio da equipe de pesquisadores que acompanhou a validação.

Observou-se também, que os alunos demonstraram interesse e entusiasmo em jogar. Como o número de computadores era menor do que o número de alunos, os mesmos realizaram as atividades em duplas. Observou-se que os alunos formavam as duplas por gênero (meninos com meninos e meninas com meninas), e que intercalavam com os colegas para jogar.

Ao término da validação foram realizadas algumas perguntas para os alunos, se tinham sugestões para melhorar o jogo, e se tinham gostado do jogo. Todos responderam que gostaram e sugeriram várias ideias para melhorar o jogo, tais como: incluir mais fases; criar um cenário de um posto de gasolina com pneus velhos; que o jogo fosse em primeira pessoa; que o personagem tivesse uma mochila a jato; que tivesse menos mosquitos e que a passagem de fase fosse mais difícil. De uma maneira geral a avaliação dos alunos foi positiva em relação ao jogo.

\section{CONSIDERAÇÕES FINAIS}

O jogo educacional digital desenvolvido neste trabalho - o "Super ZID", além de servir como uma ferramenta pedagógica de apoio aos processos de ensino e de aprendizagem em sala de aula, pode proporcionar aos usuários aumento da concentração e da habilidade motora, entre outros benefícios. Pensando-se do ponto de vista da utilização do jogo pelo professor em sala de aula, este poderá contar com uma ferramenta para auxiliá-lo em suas aulas adotando, assim, um método diferente dos tradicionais. Como o assunto abordado no jogo não é estudado em uma disciplina regular, o jogo pode ajudar não somente alunos, mas também professores que, por muitas das vezes, podem não ter muitos conhecimentos sobre as doenças transmitidas pelo mosquito Aedes Aegypti. Como normalmente o material distribuído sobre o assunto encontra-e na forma de panfletos o jogo acaba, se tornando uma ferramenta muito mais eficaz para o aprendizado, pois, as crianças já estão familiarizadas com ambientes digitais. 
Durante a primeira etapa deste trabalho, que envolveu a modelagem do ambiente lúdico do jogo, foi possível aprimorar as interfaces e, principalmente, identificar com mais clareza o propósito do jogo. Com o decorrer do desenvolvimento do projeto foram realizados estudos mais aprofundados sobre os assuntos tratados no projeto, tais como o estudo da ferramenta para o desenvolvimento do protótipo, o estudo sobre o mosquito Aedes Aegypti e como a informática tem ganhado cada vez mais espaço na educação.

$\mathrm{Na}$ segunda etapa deste trabalho foi concluído o desenvolvimento do protótipo do jogo educacional "Super Zid", com os cenários e fases definidas e a aplicação e validação do jogo com alunos na faixa etária proposta.

Acredita-se que foi possível alcançar os objetivos propostos, envolvendo o desenvolvimento de um protótipo de jogo educacional digital. Com base na validação realizada, acredita-se que foi possível desenvolver uma ferramenta que pode vir a auxiliar no aprendizado dos alunos, de uma forma a complementar aos conteúdos estudados em sala de aula, e mostrar que é possível inserir tecnologia nas escolas sem prejudicar o ensinamento e sim melhorando o mesmo, possibilitando ao aluno mais opções de aprendizagem.

O jogo encontra-se disponível na web, no link https://carinazortea.github.io/projeto.

Como trabalhos futuros, pretende-se desenvolver melhoramentos no jogo possibilitando que o mesmo possa ser acessado em dispositivos móveis. Além disso, é possível acrescentar mais fases ao jogo e melhorar as já existentes acrescentando mais focos de criadouros do mosquito Aedes Aegypti. Outra possibilidade seria a de implementar uma versão do jogo em 3D, já que existem novas versões do Construct 2 sendo testadas em 3D.

\section{REFERÊNCIAS}

BEHAR, P. A. (2009) Modelos Pedagógicos em Educação a Distância. Artmed Editora, 2009.

CUPERSCHMID, A. R. M; HILDEBRAND, H. R (2013). Heurísticas de Jogabilidade: usabilidade e entretenimento em jogos digitais. Campinas/SP: Marketing Aumentado.

FALKEMBACH, G. A. M. (2005). Concepção e Desenvolvimento de Material Educativo Digital. Renote: Novas Tecnologias na Educação, v. 3, n. 1. CINTEDUFRGS. Disponível em: Acesso em 14 abr. 2016.

FAVERO, A. (2016) Região tem dois casos de dengue confirmados. O ALTO URUGUAI. Frederico Westphalen, 27 mar. 2016. Disponível em: $<$ http://www.oaltouruguai.com.br/publicacao-17171-

Regiao_tem_dois_casos_de_dengue_confirmados.fire>. Acesso em: 08 abr. 2016.

GEBRAN, M. P. (2009) Tecnologias educacionais. IESDE BRASIL SA.

LARSEN, G. (2016) Construct 2: Conhecendo a game engine.Disponível em: http://producaodejogos.com/conhecendo-construct-2/. Acesso em: 19 de Jun 2016. 
PARREIRA, F. J.; FALKEMBACH, G. A. M.; SILVEIRA, S. R. (2016) Construção de Jogos Educacionais Digitais e Objetos de Aprendizagem: Um Estudo de Caso empregando Adobe Flash, HTML 5, CSS, JavaScript e Ardora.Rio de Janeiro: Ciência Moderna. No prelo.

RIBEIRO, V. G.; ZABADAL, J. R. S. (2010). Pesquisa em Computação: uma abordagem metodológica para trabalhos de conclusão de curso e projetos de iniciação científica. Porto Alegre: Editora UniRitter.

SCIRRA (2016). Construct 2. Disponível em: <https://www.scirra.com/manual/1/construct-2>. Acesso em: 12 abr. 2016.

TIELLET, C. A. et al. (2007) Atividades digitais: seu uso para o desenvolvimento de habilidades cognitivas. RENOTE, v. 5, n. 1. 